\title{
Restriction Enzyme Analysis of Mitochondrial DNA of Members of the Genus Aspergillus as an Aid in Taxonomy
}

\author{
By M. KOZŁOWSKI, AND P. P. STȨPIEŃ* \\ Department of Genetics, University of Warsaw, Al. Ujazdowskie 4, 00478 Warsaw, Poland
}

(Received 5 January 1981; revised 28 June 1981)

Restriction endonuclease cleavage patterns of mitochondrial DNA from seven species of the genus Aspergillus (A. nidulans, A. wentii, A. awamori, A. niger, A. oryzae, A. tamarii and $A$. echinulatus) have been compared in order to test the phylogenetic relationships between these species. The fraction of restriction fragments common between all pairs of species from this set ranged from 0 to 1 . The use of this approach for the taxonomy of the genus Aspergillus is discussed. The postulated phylogenetic relationships differ significantly in two cases from the classification of the genus presented by Raper \& Fennell (1965).

\section{INTRODUCTION}

Classification and delineation of species in the genus Aspergillus presented by Thom \& Raper (1945) and by Raper \& Fennell (1965) has been based on differences in morphology and growth characteristics. According to Fennell (1977), the 18 groups of the genus Aspergillus are not accredited taxa and serve only as convenient slots for characterization of the strains. Because of the importance of the genus for industry, clinical medicine and food production, many physical and biochemical investigations on various species have been performed, and different approaches have been used in order to provide better means of classification and better understanding of the evolution of the genus Aspergillus. Cell wall composition (Bartnicki-Garcia, 1968), protein electrophoresis (Kulik \& Brooks, 1970), analysis of pyrolysis products (Vincent \& Kulik, 1973), physicochemical analysis of nucleic acids (Storck \& Alexopoulos, 1970) and other methods have been employed, but it seems that the phylogenetic relationships between the groups of the genus Aspergillus are still to be established (Fennell, 1977).

In this paper we present the application of restriction enzyme digestions of mitochondrial DNA for investigation of different species of the genus Aspergillus. Mitochondrial DNA is a circular molecule, varying in length between 15 and $120 \times 10^{3}$ base pairs $(\mathrm{kb})$ in different organisms. It codes for mitochondrial rRNAs, tRNAs and a small number of proteins (Linnane \& Nagley, 1978). The small size of the mitochondrial DNA makes it suitable for restriction enzyme analysis, and comparison of the degree of base substitutions should provide more information about the phylogeny of the species as it reflects the primary events in evolution, i.e. changes in DNA sequence. A similar approach has been used for different species of the rat (Hayashi et al., 1979) and maize (Timothy et al., 1979) and for mammals (Brown et al., 1980).

The aim of our work was not to present data for taxonomy of the whole genus, but to test whether restriction enzyme analysis of mitochondrial DNA could be used for this purpose, and if it could, how our results would fit into the delineation of Aspergillus species made by Raper \& Fennell (1965). We therefore tested the following strains: $A$. nidulans from the $A$. nidulans group; $A$. wentii from the $A$. wentii group; $A$. awamori and $A$. niger from the $A$. niger group; $A$. oryzae and $A$. tamarii from the $A$. flavus group. In addition, we have used, for comparison, the data of Earl et al. (1980) on A. echinulatus from the A. nidulans group. 
Strains. Aspergillus nidulans Eidam Wint. strain was from the collection of the Department of Genetics, University of Warsaw. All the other strains (A. wenti, A. tamarii, A. oryzae, A. luchuensis s. awamori and $A$. niger) were from the collection of the Institute for Fermentation Industry, Warsaw. We shall use the name $A$. awamori for $A$. luchuensis s. awamori. All strains were carefully checked for their identity according to Raper \& Fennell (1965) and Thom \& Raper (1945).

DNA preparation and analysis. Plasmids pBS78 and pH3 (Bartnik et al., 1979; Küntzel et al., 1980) containing cloned fragments of the mitochondrial genome of $A$. nidulans were from the collection of the Department of Genetics. Preparation of mitochondrial DNA from mycelial pads was performed as described by Stępien et al. (1978) and modified by Hahn et al. (1979). Digestion with restriction enzymes and agarose gel electrophoresis were performed as described by Bartnik et al. (1979). Hybridization experiments were performed according to Southern (1975). ${ }^{32} \mathrm{P}$-labelled RNA was prepared by in vitro transcription of pBS78 and pH3 plasmids as described by Tyler et al. (1974), using guanosine $5^{\prime}-\left[\alpha^{-32} \mathrm{P}\right]$ triphosphate (Amersham; $3000 \mathrm{Ci} \mathrm{mmol}^{-1}, 110 \mathrm{TBq}^{-1}$ $\mathrm{mmol}^{-1}$ ). Autoradiography was performed in a Kodak X-omatic Regular Cassette with intensifying screens using Kodak X-omat R films. Restriction endonucleases EcoRI and HindIII were produced by POCH, Gliwice, Poland.

\section{RESULTS AND DISCUSSION}

Two different kinds of test were performed. First, mitochondrial DNA from each strain was digested to completion with a mixture of EcoRI and HindIII restriction enzymes and the resulting DNA fragments were resolved by agarose gel electrophoresis, photographed and their molecular weights were established using restriction fragments of bacteriophage $\lambda$ DNA as standards (Figs 1 and 2). Second, the DNA from gels was transferred to nitrocellulose filters by the method of Southern (1975) and hybridized to two different radioactive probes RNA obtained by in vitro transcription of plasmid $\mathrm{pH} 3$ or pBS78 containing the genes for 16S and 23S mitochondrial rRNA, respectively (Lazarus et al., 1980). This approach enabled us to confirm the identity of some DNA bands in the size regions of $1.6-1.9 \mathrm{~kb}$ and of $4 \mathrm{~kb}$.

Table 1 presents the comparison of fractions of common bands between all the species tested. This fraction $(F)$ was calculated according to the formula:

$$
F=2 c_{\mathrm{XY}} /\left(u_{\mathrm{X}}+u_{\mathrm{Y}}+2 c_{\mathrm{XY}}\right)
$$

where $c_{\mathrm{XY}}$ represents the number of bands common to strains $\mathrm{X}$ and $\mathrm{Y}$, and $u_{\mathrm{X}}$ and $u_{\mathrm{Y}}$ represent numbers of unique bands. The fraction of conserved bands provides information on phylogenetic relationships between species.

Our data confirm a close relationship of the species $A$. echinulatus and $A$. nidulans, both belonging to the $A$. nidulans group. Two members of the $A$. flavus group, $A$. oryzae and $A$. tamarii, also show a close homology. Unexpectedly, $A$. wentii shows an identical restriction pattern with $A$. tamarii; this result indicates an extremely close phylogenetic relationship between the two species. All members of the $A$. flavus and $A$. nidulans groups tested in this work have about $25 \%$ of the bands in common and show less homology to $A$. niger and $A$. awamori (both from the $A$. niger group). The phylogenetic distance between the $A$. nidulans and $A$. flavus groups seems to be less than the distances between $A$. flavus and $A$. niger and between $A$. niger and $A$. awamori. The last result is striking, as $A$. niger and $A$. awamori are classified together within the $A$. niger group and one might expect more homology between the two species.

It might be of interest to calculate sequence divergence i.e. the degree of base substitutions per base pair in different mitochondrial DNAs. It is, however, important to point out that the procedure of Upholt (1977) for calculating sequence divergence can be applied here only with several reservations. First, it seems that the rate of base substitutions is not equal in all parts of the mitochondrial genome (Brown et al., 1980). Second, some of the observed changes in restriction patterns might be due to insertions, as was shown for A. echinulatus by Earl et al. (1980), and as is indicated by the differences in the molecular weights of the mitochondrial genomes studied. Third, we present here restriction patterns and not restriction maps; thus there is a possiblility of misinterpretation in calculating common bands versus 


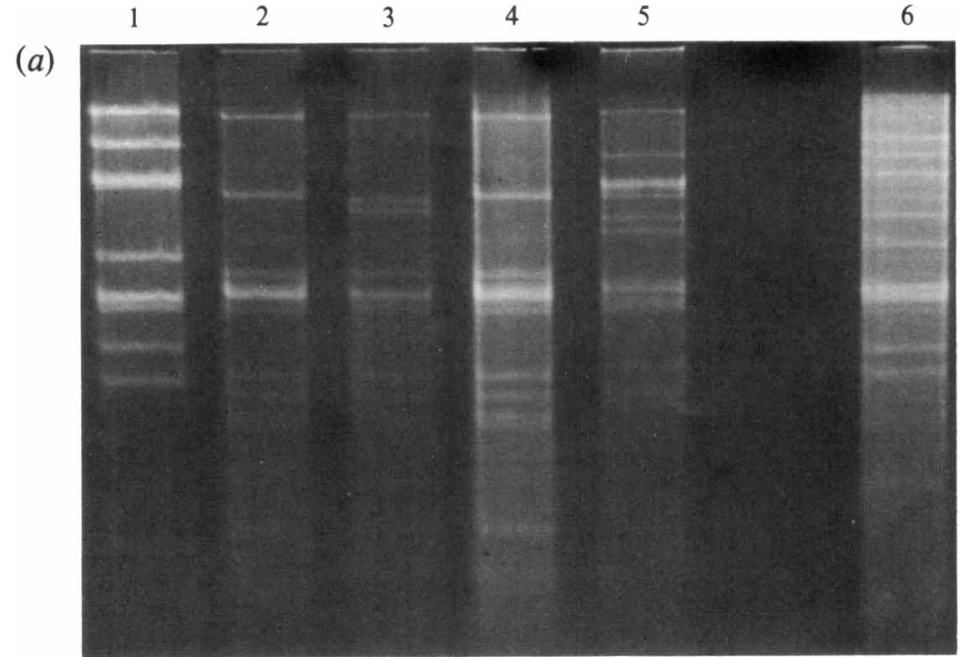

(b)

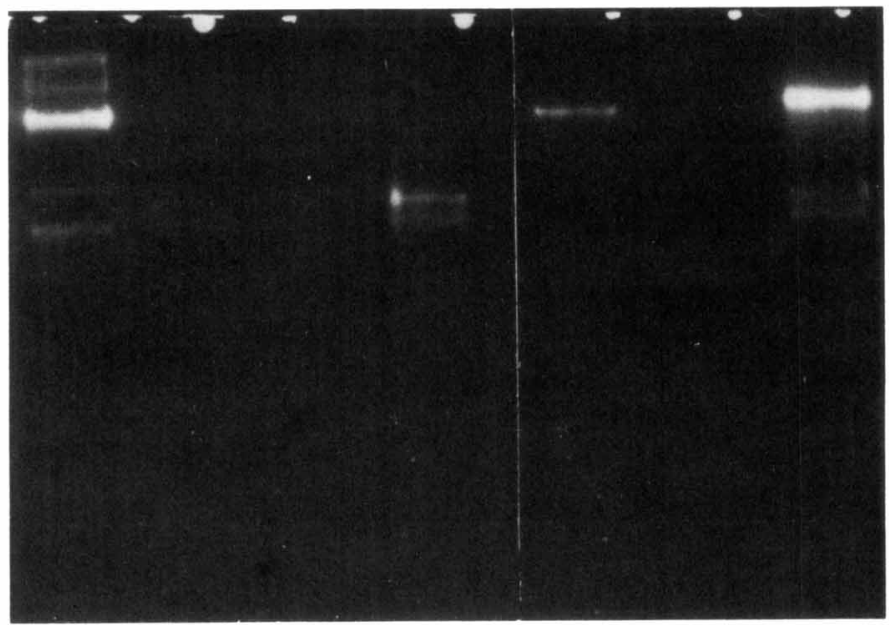

(c)

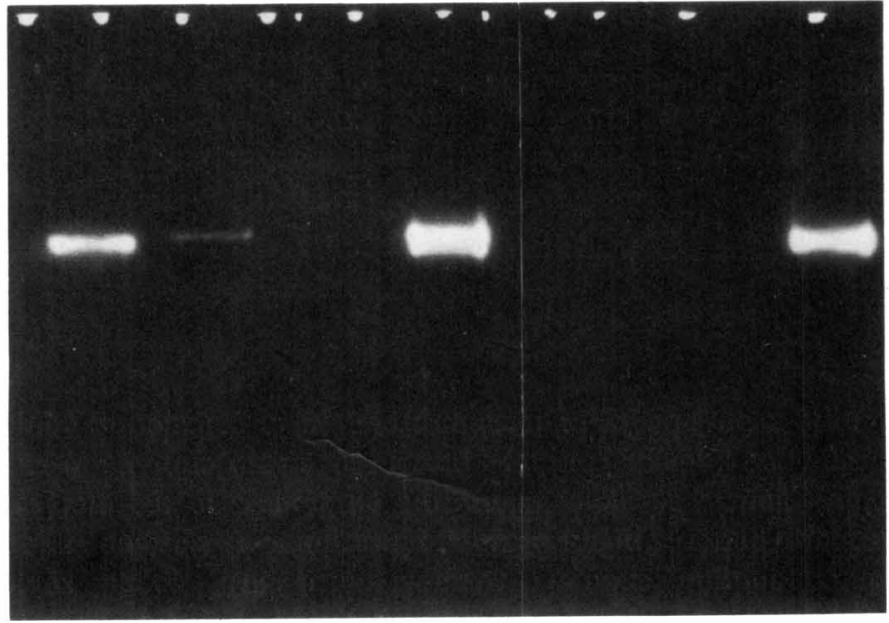

Fig. 1. EcoRI and HindIII restriction endonuclease digestion patterns of mitochondrial DNA from various aspergilli $(a)$ and their gel transfer hybridization to probes representing 16S rRNA $(b)$ and 23S rRNA (c) from $A$. nidulans. Lane $1, A$. nidulans; $2, A$. tamarii; 3, $A$. oryzae; 4, A. wentii; 5, A. awamori; 6, A. niger. 


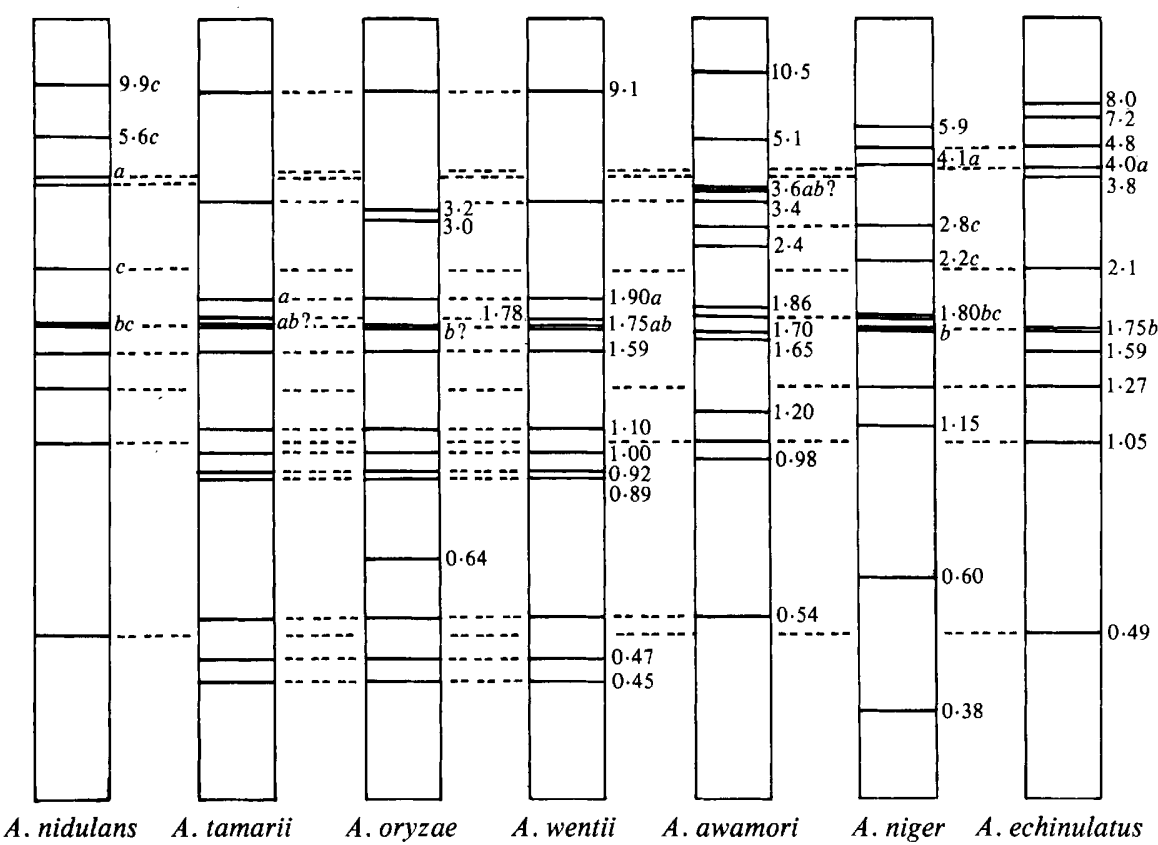

Fig. 2. A schematic diagram and molecular weights (in $\mathrm{kb}$ ) of fragments of mitochondrial DNA from various species of aspergilli generated by $E c o$ RI and $H$ indIII restriction endonucleases. [Data for $A$. echinulatus are from Earl et al. (1980).] $a$, Bands hybridizing to the radioactive probe representing $16 \mathrm{~S}$ rRNA; $b$, bands hybridizing to the radioactive probe representing $23 \mathrm{~S}$ rRNA; $c$, bands showing weak hybridization to the probe $(4.0 \mathrm{~kb}$ fragment of $A$. nidulans mitochondrial DNA containing the 16S rRNA gene and its flanking sequences) probably due to small regions of homology between different fragments of mitochondrial DNA; ?, hybridization could only be seen on the negative.

Table 1. Values of $F$ (fraction of common bands between two tested species) and p (sequence divergence) calculated for seven species of aspergilli

\begin{tabular}{|c|c|c|}
\hline Species compared & $F$ & $p(\%$ \\
\hline A. nidulans-A. tamarii & 0.24 & $8 \cdot 6$ \\
\hline A. nidulans $-A$. wentii & 0.24 & 8.6 \\
\hline A. nidulans $-A$. oryzae & 0.23 & $8 \cdot 9$ \\
\hline A. nidulans-A. awamori & 0 & - \\
\hline A. nidulans $-A$. niger & 0.25 & $8 \cdot 3$ \\
\hline A. nidulans $-A$. echinulatus & 0.78 & $1 \cdot 4$ \\
\hline A. tamarii-A. wentii & 1.0 & 0 \\
\hline A. tamarii-A. oryzae & 0.83 & $1 \cdot 1$ \\
\hline A. tamarii-A. awamori & 0.07 & $16 \cdot 5$ \\
\hline A. tamarii-A. niger & $0 \cdot 15$ & $11 \cdot 7$ \\
\hline A. tamarii-A. echinulatus & 0.26 & $8 \cdot 1$ \\
\hline A. wentii-A. oryzae & 0.83 & $1 \cdot 1$ \\
\hline A. wentii-A. awamori & 0.07 & $16 \cdot 5$ \\
\hline A. wentii-A. niger & $0 \cdot 15$ & $11 \cdot 7$ \\
\hline A. wentii-A. echinulatus & 0.26 & $8 \cdot 1$ \\
\hline A. oryzae-A. awamori & 0.07 & $16 \cdot 1$ \\
\hline A. oryzae-A. niger & $0 \cdot 14$ & 11.9 \\
\hline A. oryzae-A. echinulatus & 0.22 & $9 \cdot 1$ \\
\hline A. awamori-A. niger & $0 \cdot 14$ & 11.9 \\
\hline A. awamori-A. echinulatus & 0.07 & $16 \cdot 1$ \\
\hline A. niger-A. echinulatus & 0.24 & 8.6 \\
\hline
\end{tabular}




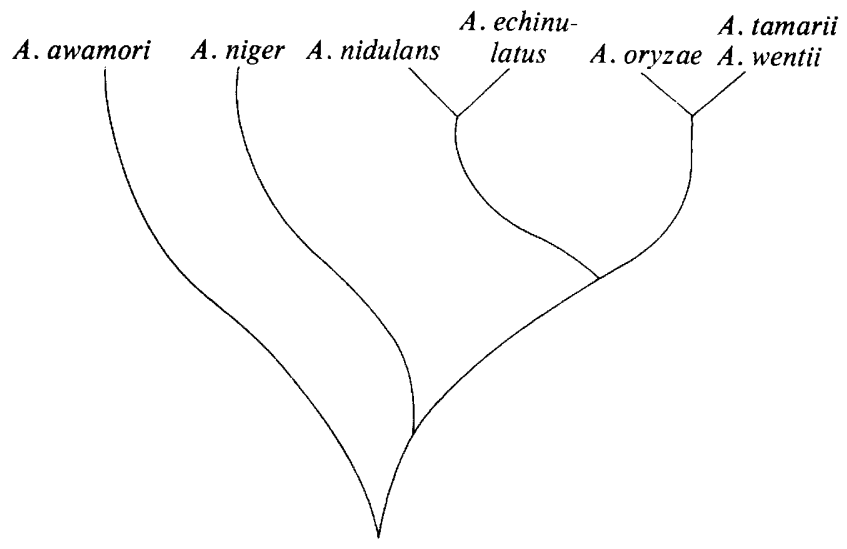

Fig. 3. A hypothetical tree of phylogenetic relationships between the tested species of the genus Aspergillus.

unique bands. For the above reasons, the values of sequence divergence $(p)$ presented in Table 1 should be treated as estimates only.

It has been established for mammals that the rate of evolution of mitochondrial DNA is 10 times faster than that of nuclear DNA (Brown et al., 1979). In that study, sequence divergence values were correlated with data from the study of fossils. In contrast to this, the rate of evolution of fungal mitochondrial DNA is not known. However, if we assume that the rate of evolution of mitochondrial genomes from the genus Aspergillus is constant, then the values of sequence divergence are proportional to the time in evolution when the two compared species separated. On this assumption, we have constructed a hypothetical tree of phylogenetic relationships between the members of the genus Aspergillus tested in our laboratory (Fig. 3).

Some comments on the credibility of the results obtained should be made. Molecular weights of DNA fragments are usually calculated with an accuracy of about $5 \%$, but it is important to point out that the mitochondrial DNA molecule is circular, and that identifying two bands as being identical can often be done not only by comparing their molecular weights, but also by comparing their relative positions with respect to other bands, i.e. the band pattern. Additional information can be obtained from hybridization data or from comparison of restriction patterns obtained with different mixtures of enzymes. We tested such patterns using digestion of mitochondrial DNAs with HindIII alone (data not shown), and the results confirmed our conclusions.

It is difficult to estimate the error of our calculation of the fraction $F$ (and of sequence divergence $p$, as $p$ is a function of $F$ ). This is due to the fact that when $F$ approaches 1 , the accuracy reaches its maximum. When $F$ is significantly lower than 1 , the possibility of misinterpretation of $c_{\mathrm{XY}}$ is greater, and so is the error. If we assume misinterpretation of two bands, then the error is 0.07 . Any such error would not affect our conclusions on the phylogenetic relationships between the tested species.

All the species examined were very carefully checked for their identity using the methods described by Raper \& Fennell (1965). However, we consider that investigations on other members of this group are needed in order to establish the divergence within the genus Aspergillus; unfortunately, we have no such strains in our collection.

We believe our data clearly show that the use of restriction enzyme analysis of mitochondrial DNA would be a very useful method in the taxonomy of the genus Aspergillus. In our small sample of seven species the values of $F$ (the fraction of common bands) from the array of comparisons varied from 0 to 1 in an almost continuous fashion. This means that in the genus Aspergillus both close relationships and relatively great phylogenetic distances can be estimated using this method. We hope, therefore, that this approach will be continued and will provide a useful aid for the taxonomy of the genus Aspergillus. 
This project was supported by the Polish Academy of Sciences. We thank Dr H. Halweg from the Institute of Tuberculosis for her help in identifying the species of Aspergillus.

\section{REFERENCES}

BARTNICKI-GARCIA, S. (1968). Cell wall chemistry, morphogenesis and taxonomy of fungi. Annual Review of Microbiology 22, 87-108.

Bartnik, E., Pieniazzek, N. J. \& Stȩ̧ień, P. P. (1979). Molecular cloning of the 4.2 Md EcoRI fragment of Aspergillus nidulans mitochondrial DNA. Molecular and General Genetics 171, 75-78.

Brown, W. M., George, M., JR \& Wilson, A. C. (1979). Rapid evolution of animal mitochondrial DNA. Proceedings of the National Academy of Sciences of the United States of America 76, 1967-1971.

Brown, W. M., Ferris, D. S., George, M., JR \& WAND, A. (1980). The evolution of vertebrate mitochondrial DNA: frequency and distribution of base substitutions in the mitochondrial genome of mammals. In Abstracts of the 12th International Bari Conference on The Organization and Expression of the Mitochondrial Genome, Martina Franca, Italy, p. 14.

Earl, A. J., Turner, G., Croft, J. H., Lazarus, C. M., LüNSDORF, H. \& KüNTZEL, H. (1980). Physical recombination of mt DNA accompanies interspecific transfer of cytoplasmatically inherited markers between members of the Aspergillaceae. In Abstracts of the 12th International Bari Conference on The Organization and Expression of the Mitochondrial Genome, Martina Franca, Italy, p. 49.

FenNELl, D. I. (1977). Aspergillus taxonomy. In Genetics and Physiology of Aspergillus, pp. 1-21. Edited by J. E. Smith \& J. A. Pateman. New York: Academic Press.

Hahn, U., Lazarus, C. M., LÜNSDoRf, H. \& KÜNTZEL, H. (1979). Split gene for mitochondrial 24 S ribosomal RNA of Neurospora crassa. Cell 17, 191-200.

Hayashi, J., Yonekawa, H., Gotoh, O., Tagashira, Y., MoriWaKI, K. \& Yoshida, T. H. (1979). Evolutionary aspects of variant types of rat mitochondrial DNAs. Biochimica et biophysica acta 564 , 202-211.

KÜNTZEL, H., BASAK, N., HAHN, U., IMAM, G., Köchel, H., Lazarus, C. M., LüNSDORF, H., Piechulla, B., Bartnik, E., Biderman, A. \& STȨPIEN', P. P. (1980). The mitochondrial genome of Aspergillus nidulans. In The Organization and Expression of the Mitochondrial Genome, pp. 79-86. Edited by A. M. Kroon \& C. Saccone.
Amsterdam: Elsevier/North-Holland Biomedical Press.

Kulik, M. M. \& BRooKs, A. G. (1970). Electrophoretic studies of soluble proteins from Aspergillus spp. Mycologia 62, 365-376.

Lazarus, C. M., LÜNSDORF, H., Hahn, U., StȩPień, P. P. \& KüNTZEL, H. (1980). Physical map of Aspergillus nidulans genes coding for ribosomal RNA: an intervening sequence in the large rRNA cistron. Molecular and General Genetics 177, 389-397.

LinNANe, A. W. \& NAgley, P. (1978). Structural mapping of mitochondrial DNA. Archives of Biochemistry and Biophysics 187, 277-289.

RAPER, K. B. \& FENNELL, D. I. (1965). The genus Aspergillus. Baltimore: Williams \& Wilkins.

SoutherN, E. M. (1975). Detection of specific sequences among DNA fragments separated by gel electrophoresis. Journal of Molecular Biology 98, 503-517.

STȨPień, P. P., Bernard, U., CoOKe, H. J. \& KÜNTZEL, H. (1978). Restriction endonuclease cleavage map of mitochondrial DNA from Aspergillus nidulans. Nucleic Acids Research 5, 317-330.

Storck, R. \& Alexopoulos, C. J. (1970). Deoxyribonucleic acid of fungi. Bacteriological Reviews 34, 126-154.

THOM, C. \& RAPER, K. B. (1945). A Manual of the Aspergilli. Baltimore: Williams \& Wilkins.

Timothy, D. H., Levings III, C. S., Pring, D. R., Conde, M. F. \& Kernicle, J. L. (1979). Organelle DNA variation and systematic relationships in the genus Zea: Teosinte. Proceedings of the National Academy of Sciences of the United States of America 76, 4220-4224.

Tyler, B., Beleo, A. B. \& Magasanik, B. (1974). Activation of transcription of hut DNA by glutamine synthetase. Proceedings of the National Academy of Sciences of the United States of America 71, 225-229.

UPHOLT, W. B. (1977). Estimation of DNA sequence divergence from comparison of restriction nuclease digests. Nucleic Acids Research 4, 1257-1265.

Vincent, P. G. \& Kulik, M. M. (1973). Pyrolysisgas-liquid chromatography of fungi: numerical characterization of species variation among members of the Aspergillus glaucus group. Mycopathologia et mycologia applicata 51, 251-265. 